\title{
Facile design of heat-triggered shape-memory ethylene-acrylic acid copolymer/chloroprene rubber thermoplastic vulcanizates
}

\author{
F. F. Liu, Y. T. Sun, Z. B. Wang* \\ College of Material Science \& Engineering, Qingdao University of Science \& Technology, 266042 Qingdao, P. R. China
}

Received 19 July 2019; accepted in revised form 9 September 2019

\begin{abstract}
Stimuli-responsive shape-memory ethylene-acrylic acid copolymer (EAA)/chloroprene rubber (CR) thermoplastic vulcanizates (TPVs) were prepared via dynamic vulcanization. Meanwhile, a simple and effective strategy was designed to achieve rapidly reconfigurable shape fixity and shape recovery for a heat-triggered shape-memory polymer (HSMP), which was derived from a typical sea-island structured EAA/CR TPVs. Field emission scanning electron microscopy (FE-SEM) showed the average diameter of CR particles in EAA/CR TPVs was 3 8 $\mu \mathrm{m}$. In this work, the mechanical properties results showed that the EAA/CR TPV had high tensile strength, indicating a strong interface interaction between EAA and CR, which would inevitably improve the shape recovery $(S R)$ and shape fixing $(S F)$ ability of TPVs. This HSMP exhibited the surprising shape-memory property (shape fixity ratio $\sim 97 \%$, shape recovery ratio $\sim 95 \%$, and fast recovery speed $<30 \mathrm{~s}$ ). The dynamic mechanical behavior and stress relaxation behavior of EAA/CR TPVs were characterized, and the results demonstrated that the high modulus value supported the improvement of $S F$ ratios, and with the decrease continuously of EAA in the EAA/CR TPVs, the low-stress relaxation ratio stimulated the improvement of $S R$ ratios of the EAA/CR TPVs. This novel HSMP expected to open up a wide range of potential applications in smart devices.
\end{abstract}

Keywords: mechanical properties, chloroprene rubber, ethylene-acrylic acid copolymer, shape-memory polymers, thermoplastic vulcanizate

\section{Introduction}

An emerging class of new smart materials is the socalled 'shape-memory polymers (SMPs)'. In the recent decades, SMPs have gained much attention and technological interest in the academia and industry because of their superior and desirable qualities, such as low density, potentially recyclable at relatively low cost, high recoverable strain within a wide range of stimuli, transparence and easier processing [1]. As a result of their easy tailoring and programming, SMPs have been extensively applied in drug releasing systems, self-healing materials, smart fabrics, intelligent packaging, biomedical devices, sensors, and actuators [2-7], etc. SMPs are also a kind of stimuli-responsive materials, which can recover to their permanent shape from large deformations by exposure to various external stimuli such as temperature, light, $\mathrm{pH}$, moisture, electric and magnetic field [2, 8-13], etc. Among all the stimulus-triggered shape-memory polymers, the heat-triggered shapememory polymers (HSMPs) are the most concerned and attractive SMPs due to their feasible shapememory process and broad applications.

According to the classic shape-memory mechanism, HSMPs not only exhibited the optimal switch points but also showed the controllable recovery kinetics, which can be perfectly realized by regulating the temperature and fabricating a phase-separation or 
crosslinked structure containing switching and permanent segments [14-16]. HSMPs basically contain at least two structural domains, one is the switching domain which is responsible for fixing the temporary shape, and the other one is called the reversible domain which is easily deformed to provide the driving force for recovery $[17,18]$.

Generally, the rationale to the observed shape-memory behavior lied in the presence of the switching temperatures $\left(T_{\mathrm{sw}}\right)$, such as the glass transition temperature $\left(T_{\mathrm{g}}\right)$ and crystalline melting temperature $\left(T_{\mathrm{m}}\right)$, the mobility of molecular chains allows HSMPs to be shaping. The dual-shape HSMPs could be fixed in its temporary shape under an external force after cooling down to the specific deformation temperature $\left(T_{\mathrm{d}}\right)$ from the programming temperature above its $T_{\mathrm{g}}$ or $T_{\mathrm{m}}$. Then temporary shape was recovered from the orientated samples while the recovery temperature $\left(T_{\mathrm{r}}\right)$ was increased again to above the $T_{\mathrm{sw}}$ $[19,20]$, which was attributed to the entropy effect because the active molecular chains energetically prefer to return to the most disordered conformation [21-24]. Typical HSMPs are usually synthetic block copolymers, in which physically or chemically crosslinked hard segments create permanent memory shape and soft segments provide switching domains [2527]. Although the architecture of block copolymers can be designed to offer the required shape-memory effect (SME), the relatively expensive synthesis process limited their broad utilization more or less. Shape-memory blends consist of an amorphous polymer serving as the memory phase and a crystalline or semi-crystalline polymer as the switching phase. However, most of the plastic/plastic blending systems have the drawback of lacking a strong shape recovery driving force. It is reasonable that a cross-linked rubber component with strong resilience is helpful to improve the SME of a blending system. Thermoplastic vulcanizate (TPV), a plastic/rubber blend in which rubber components are cross-linked, is generated from dynamic vulcanization [28-30]. Differing from small molecules, plastic melts cannot cause swelling of a cross-linked rubber. Thus, when rubber was cross-linked during melt blending, it inevitably results in a typical sea-island structure in which the cross-linked rubber is in particulate forms dispersing in plastic continuous phase [31]. Usually, this seaisland microstructure is hard to achieve a strong interfacial adhesion in the blend to hold the highly deformed rubber phase in temporary shape, because in most cases the phase interface is not powerful enough to perform the SME behavior [32]. As reported by Xu et al. [33] a strong interface originating from in situ compatibilization was critical to the shape recovery of EPDM/PP/ZDMA TPVs. Considering reduction of the rubber particle size, the largely increased contact areas between the EPDM and PP phases also added contributions to the SME. However, if the morphology structure of cross-linked rubber could be controlled as a continuous phase, as well as achieving a largely improved interfacial adhesion with plastic phase, the plastic/rubber blends could be used as HSMPs directly.

Ethylene-acrylic acid copolymer (EAA) is a thermoplastic resin with the merits of excellent adhesion and easy processing, which is widely used in packaging, adhesives, and sealing [34-36]. Moreover, the semicrystalline EAA matrix served as the switching phase in TPVs based SMPs. Chloroprene rubber (CR), a kind of polar rubber, with its exceptional physical and chemical properties [37-39], is categorized to be suitable for providing strong shape recovery.

In this work, we presented the facile design strategy of heat-triggered shape-memory EAA/CR TPVs via dynamic vulcanization. EAA/CR TPVs with a seaisland structure were prepared, in which EAA was used as the switching phase, and cross-linked CR phase could provide strong resilience to achieve shape recovery. The influence of $T_{\mathrm{d}}, T_{\mathrm{r}}$ on the SME behavior, microstructure morphology and shape-memory mechanism were investigated systematically. The novel HSMP exhibited impressive SME and a high potential for using in smart devices.

\section{Experimental}

\subsection{Materials}

EAA, grade $\mathrm{N} 300\left(T_{\mathrm{m}}=106.4{ }^{\circ} \mathrm{C}, 9.7 \mathrm{wt} \%\right.$ acrylic acid content), was obtained from Dow Chemical Co. Ltd., US, with a melt flow index (MFI) of $8.5 \mathrm{~g}$ $10 \mathrm{~min}^{-1}\left(190^{\circ} \mathrm{C} 2.16 \mathrm{~kg}^{-1}\right)$. CR, SN244X type, the Mooney viscosity $\left(\mathrm{ML}_{1+4}\left(100^{\circ} \mathrm{C}\right)\right)$ is 75 , was commercially obtained from Shanna synthetic rubber Co. Ltd., Shanxi, China. Zinc oxide (ZnO) and Magnesium oxide $(\mathrm{MgO})$ were used as vulcanizing agents and obtained from NewLe Qinshi Zinc Co. Ltd., Xinle, China. Stearic acid was used as a softening agent and obtained from Wanyou Co. Ltd., Zibo, China. $\mathrm{N}$-Phenyl-2-naphthylamine (antioxidant D) was used as an antioxidant and supplied by Shengao Chemical Co. Ltd., Caoxian, China. 


\subsection{Preparation of EAA/CR TPVs}

Commercially available EAA and CR, as above, were used for the preparation of the blends. The concentrations for cross-linking the CR system are expressed in parts per hundred rubber by weight [phr]. The metallic oxides-containing accelerating system recipe consisted of the following ingredients: 100 phr CR, 5.0 phr ZnO, 4.0 phr MgO, 2.0, 0.5 phr SA, antioxidant $\mathrm{D}$.

Firstly, the CR rubber containing the cross-linking ingredients was compounded in a two-roll mill (X(S) K-160, Shanghai Qun Yi Rubber Machinery Co. Ltd., China) at room temperature. After 3 min of mixing time, the pre-blends were removed from the mixer. Secondly, the requisite quantities of EAA were charged into the mixer at a rotor speed of $43 \mathrm{rpm}$ (SY-6215-AL, Shi Yan precision instruments Co. Ltd., China) and allowed to melt. After $1 \mathrm{~min}$, the CR based pre-blend was added, the viscosity of the CR phase increases quickly due to the initiation of crosslink reaction and the phase morphology is not stable at this period. The mixing was continued at $165^{\circ} \mathrm{C}$ for another $8 \mathrm{~min}$ to allow the dynamic vulcanization, and the $\mathrm{CR}$ phase is gradually broken down into dispersed particles by initially large $\mathrm{CR}$ entities under the local stress that evolved during melt-mixing, the phase morphology is stable then. Furthermore, in our experiment, the dynamically vulcanized EAA/CR blends were thermoplastic and could all be melted and molded repeatedly, indicating that the dynamically vulcanized blends were thermoplastic and the crosslinked CR particles were dispersed finely in the EAA matrix. Moreover, the EAA/CR weight ratio was varied from $40 / 60$ to $80 / 20$. Finally, the compound was removed from the mixer and passed through a cold two-roll mill in the molten state to obtain sheet samples about $2 \mathrm{~mm}$ thick. Then the sheet was compression-molded under a pressure of $15 \mathrm{MPa}$ at $170^{\circ} \mathrm{C}$ for $8 \mathrm{~min}$ in a plate vulcanizing machine (50 T, Shanghai Qun Yi Rubber Machinery Co. Ltd.), followed by cold compression in another molding machine (SKZ401, Jiangdu Kaiyuan Machinery Co. Ltd.) for 8 min. Dumbbell-like test specimens were die-cut from the compression-molded sheet and used for testing after $24 \mathrm{hrs}$. CR static vulcanizate for comparison, using the same acceleration system recipe, was prepared in a compression-molding machine under the preparation condition of $170{ }^{\circ} \mathrm{C}$ for $8 \mathrm{~min}$.
Table 1. Various EAA/CR TPVs composition.

\begin{tabular}{|c|c|c|c|}
\hline TPV No & $\begin{array}{c}\text { EAA } \\
{[\mathbf{w t} \%]}\end{array}$ & $\begin{array}{c}\text { CR } \\
{[\mathbf{w t} \%]}\end{array}$ & Designation \\
\hline 1 & 40 & 60 & E4C6 \\
\hline 2 & 50 & 50 & E5C5 \\
\hline 3 & 60 & 40 & E6C4 \\
\hline 4 & 70 & 30 & E7C3 \\
\hline 5 & 80 & 20 & E8C2 \\
\hline
\end{tabular}

For brevity, TPVs were coded according to the EAA/ $\mathrm{CR}$ weight ratios; e.g., E6C4 represented a TPV specimen in which the EAA/CR weight ratio was 60/40. Details of the EAA/CR TPVs compositions were given in Table 1.

\subsection{Characterizations}

\subsubsection{Microscopy analysis}

The morphological study was carried out by using field-emission scanning electron microscopy (FESEM, JSM-6700F, Japan Electron Optics Laboratory Co., Ltd., Japan). For the etched specimens, the EAA phase was extracted by immersing the EAA/CR TPVs into xylene at $130^{\circ} \mathrm{C}$ for $3 \mathrm{hrs}$. Then the samples were ultrasonicated for $5 \mathrm{~min}$ and dried in a vacuum oven at $40{ }^{\circ} \mathrm{C}$ for $24 \mathrm{hrs}$. At last, the etched surfaces and the fracture surfaces and longitudinal stretching surface of the specimens were collectively sputtered with thin layers of platinum and imaged by using the FE-SEM.

\subsubsection{Mechanical properties}

The tensile strength of dumbbell-shape specimens at room temperature $\left(\sim 25^{\circ} \mathrm{C}\right)$ was characterized by a universal testing machine (TCS-2000, GoTech Testing Machines Inc., China). The test speed was kept at $500 \mathrm{~mm} / \mathrm{min}$, according to the ASTM D412 standard. Tensile tests of E6C4 specimens at higher temperatures $\left(25,65,80,95\right.$ and $\left.110^{\circ} \mathrm{C}\right)$ also were carried out by using a universal testing machine (Al7000-S, GoTech Testing Machines Inc., China). After equilibrating at target temperature for $15 \mathrm{~min}$, samples were stretched at the same speed until the strain/ stress limit was reached (if unbroken). The thicknesses of the dumbbell-shaped sample sheets were $2 \mathrm{~mm}$. Tensile tests at elevated temperature were repeated at least three times to ensure reproducibility, and the stress-strain curves were recorded.

\subsubsection{SME measurement}

SME measurement was conducted according to the following steps (Figure 1), (a) drawing two distance 

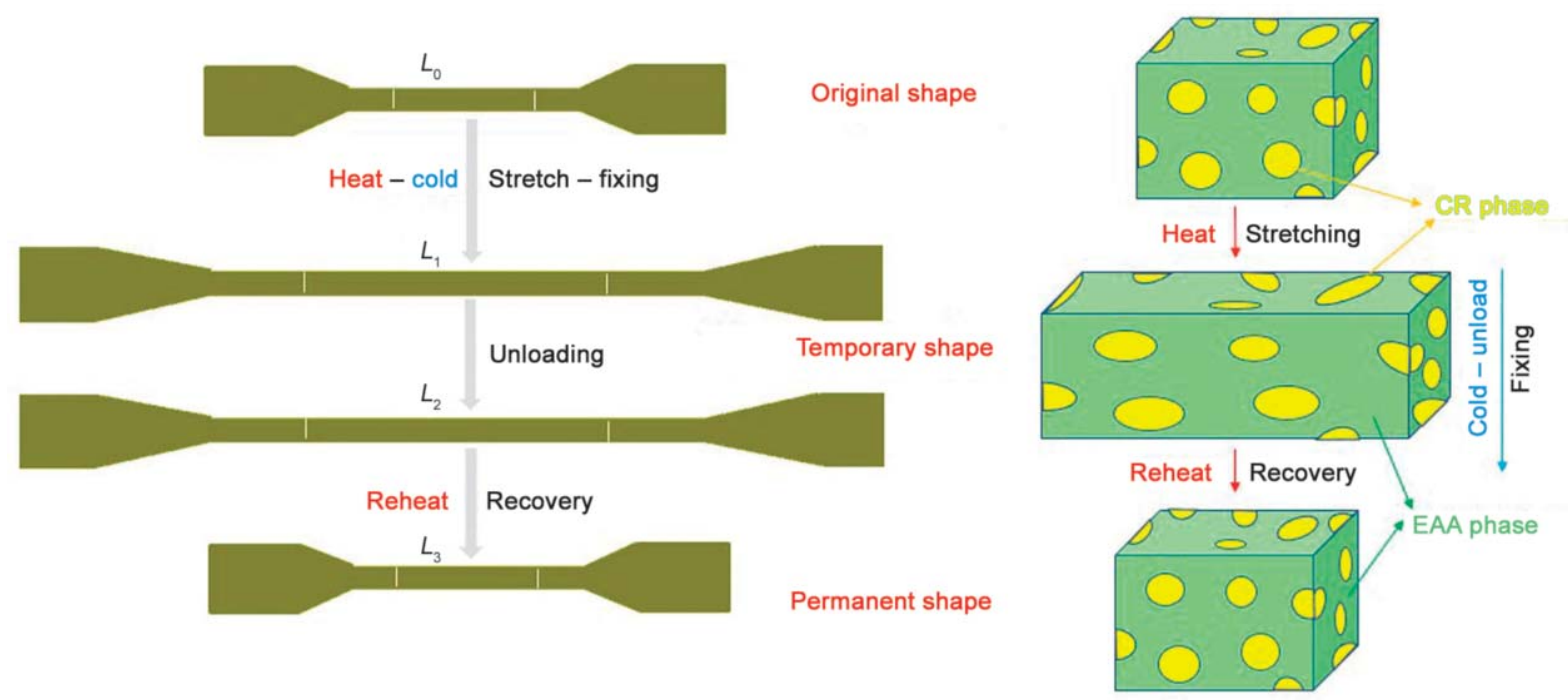

Figure 1. Schematic describing and illustration of SME measurement of EAA/CR TPVs.

lines of $20 \mathrm{~mm}$ at the center of a dumbbell specimen, which was marked as $L_{0}$; (b) the marked dumbbell specimen was placed at oil bath in deformation temperature $\left(T_{\mathrm{d}}\right)$ for $10 \mathrm{~min}$ to reach an equilibrium before stretching; (c) the marked $20 \mathrm{~mm}$ was elongated to $100 \%$; (d) the elongated specimen was cooled down to $1{ }^{\circ} \mathrm{C}$ under loading, and the marked distance was recorded as $L_{1}$; (e) upon removal of the applied force to determine the shape fixing and $24 \mathrm{hrs}$ later, the marked distance was recorded as $L_{2}$; (f) the specimen was heated to determine the shape recovery, 5 min later, the marked distance was recorded as $L_{3}$. The shape fixity $(S F)$ and shape recovery $(S R)$ ratios were calculated according to Equations (1) and (2), respectively:

$S F=\frac{L_{2}-L_{0}}{L_{1}-L_{0}} \cdot 100 \%$

$S R=\frac{L_{2}-L_{3}}{L_{2}-L_{0}} \cdot 100 \%$

Five specimens were measured to achieve the average value. The shape-memory test in our research was achieved in a precisely temperature-controlled oil bath environment, and the schematic describing of the SME measurement is shown in Figure 1.

\subsubsection{Differential scanning calorimetry (DSC)}

The thermal properties of series EAA/CR TPVs were evaluated by differential scanning calorimetry using a DSC Q20 (TA Instruments). The samples (5 10 mg) were first heated from 40 to $140^{\circ} \mathrm{C}$, kept for five minutes to eliminate the thermal history, cooled down to $-60^{\circ} \mathrm{C}$, and then heated again to $140^{\circ} \mathrm{C}$. The heating rate was fixed at $10^{\circ} \mathrm{C} / \mathrm{min}$, and the cooling rate was fixed at $20^{\circ} \mathrm{C} / \mathrm{min}$ under a nitrogen atmosphere. Above all, the crystallization temperature $\left(T_{\mathrm{c}}\right)$ was calculated by the enthalpy from the first cooling scan, and $T_{\mathrm{m}}$ was calculated by the enthalpy of fusion from the second heating scan.

\subsubsection{X-ray diffraction (XRD)}

The samples were characterized using XRD (XRD with $\mathrm{Cu} \mathrm{K} \alpha$ radiation, $\lambda=1.54178 \AA$, D/max-2500/ PC, Rigaku Co., Ltd., Tokyo, Japan) at room temperature. The diffraction patterns were recorded in the scanning range from 10 to $60^{\circ}(2 \theta)$ using a step scan mode with steps of $0.02^{\circ}(2 \theta)$ and a time per step of $10 \mathrm{~s}$.

\subsubsection{Dynamic mechanical analysis (DMA)}

Dynamic mechanical thermal analysis system (DMTS EPLEXOR, 500N, NETZSCH GABO Instruments GmbH., Germany) was used to perform the DMA measurements. The temperature sweep of the samples was carried out in tension mode over a temperature range of -60 to $+140^{\circ} \mathrm{C}$ at a heating rate of $5^{\circ} \mathrm{C} / \mathrm{min}$. The samples were scanned at a frequency of $10 \mathrm{~Hz}$ and a strain level of $10 \%$, and the storage modulus $\left(E^{\prime}\right)$, loss modulus $\left(E^{\prime \prime}\right)$ and loss tangent $(\tan \delta)$, were determined as a function of temperature.

\subsubsection{Stress relaxation behaviors}

The stress relaxation resistance of the specimens was investigated by a universal testing machine (GT7000-S, GoTech Testing Machines Inc., China). The samples were stretched to $100 \%$ strain, and then the 
strain was kept unchanged at $100 \%$ for $600 \mathrm{~s}$ at $95^{\circ} \mathrm{C}$. The stress-time curves were recorded. During stress relaxation test, the values of stress were noted after each $30 \mathrm{~s}$ interval, and the stress relaxation ratio was calculated according to Equation (3):

Stress relaxation ratio $=\frac{\text { decay stress }}{\text { original stress }} \cdot 100 \%$

\section{Results and discussion}

\subsection{Morphology and microstructure of EAA/CR TPVs}

The schematic illustration of the strategy for realizing SME of EAA/CR TPVs is shown in Figure 1. Typical TPVs had a sea-island structure where the crosslinked rubber particles were dispersed in a continuous plastic phase, and EAA was the continuous phase, and CR was the dispersed phase in the EAA/ CR TPVs. This phase structure weakened possibly of the SME for a TPV more or less, because the phase interface was not powerful enough to support the shape-memory behavior in most cases, and a major drawback of the impact on SMPs is their comparatively low tensile strength and stiffness. However, for the EAA/CR TPV, it had certain advantages for SME including the high tensile strength and stiffness, which would provide strong support for the shape fixity and recovery.

Figure 2 shows the FE-SEM images of the EAA/CR TPVs with $60 / 40$ weight ratio. The EAA matrix phase in the surfaces of TPV has been etched and the vulcanized CR particles were observed clearly. From Figure $2 \mathrm{a}$ and $2 \mathrm{~b}$, it could be seen that the vulcanized rubber domains remained undissolved and adhered to the surface. It also could be found that the crosslinked CR particles with irregular morphologies were dispersed evenly in the thermoplastic matrix. The dimensions of the discrete CR particles were in the range of $3 \sim 8 \mu \mathrm{m}$. Figure $2 \mathrm{c}$ and $2 \mathrm{~d}$ show the tensile fractured surfaces of E6C 4 specimen. The specimen had a coarse surface with some wrinkles, which indicated that it underwent relatively ductile fracture. This implied that it has a better interfacial adhesion between EAA and CR phase. Figure $2 \mathrm{e}$ and $2 \mathrm{f}$ present the FE-SEM images of the longitudinal stretching surface of the E6C4 specimen. From Figure 2e and $2 \mathrm{f}$, it is clearly seen that more pronounced orientation textures on the longitudinal stretching surface of the E6C4 specimen appeared, which was attributed to the orientation of EAA and the successful fixation of elongated CR particles by EAA.

In summary, the above-given morphology and microstructure of TPVs indicated better compatibility and the higher interfacial adhesion between EAA and $\mathrm{CR}$, which played a crucial role in the shapememory behavior for the EAA/CR TPVs.

\subsection{Mechanical properties of EAA/CR TPVs}

Figure 3 displays the stress-strain behaviors of EAA resin and series EAA/CR TPVs. From Figure 3, the stress-strain curves of different EAA/CR TPVs were

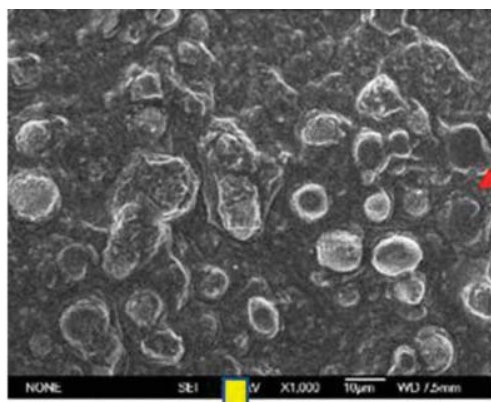

a)

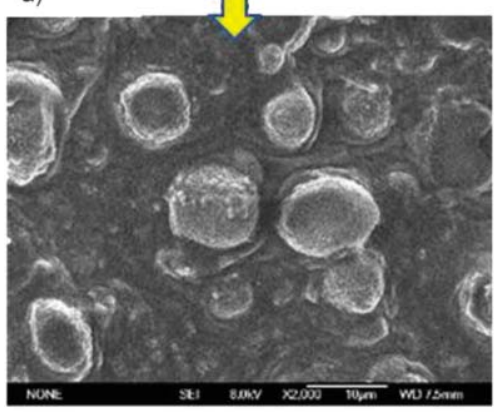

b)
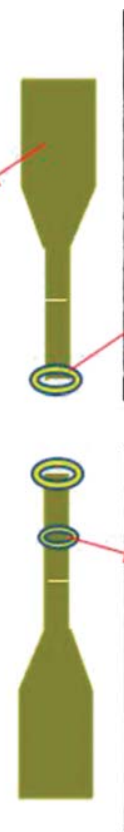

e)

c)
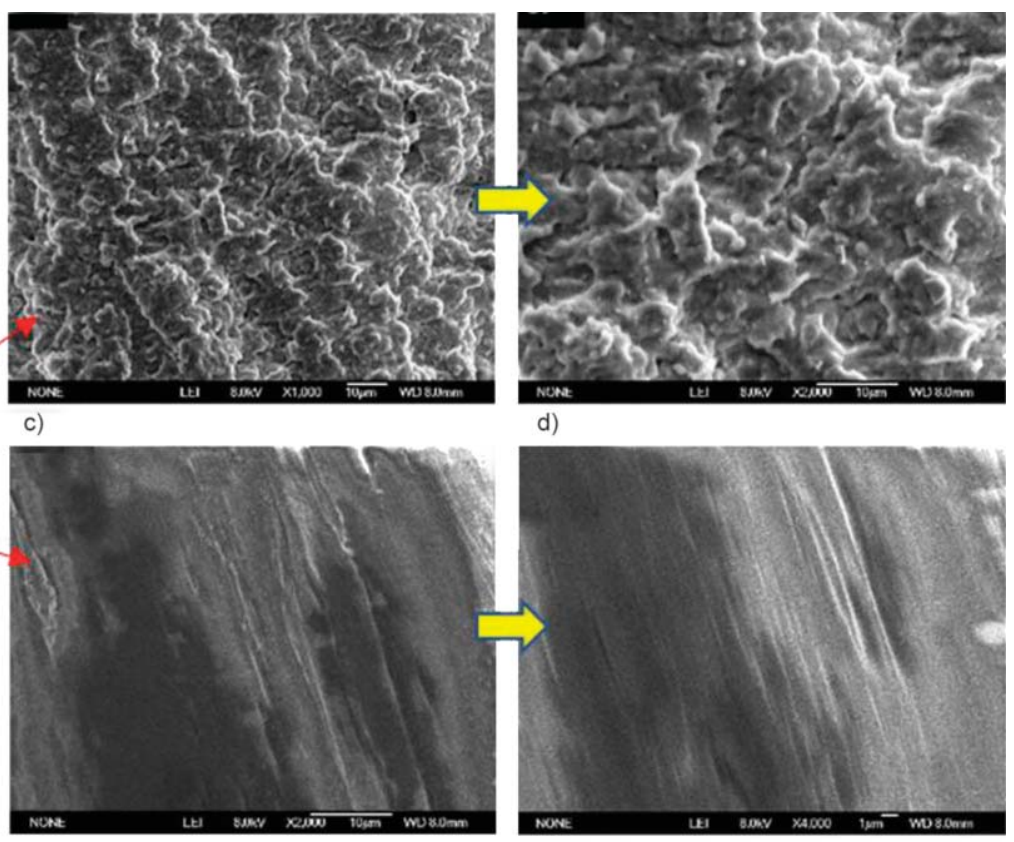

d)

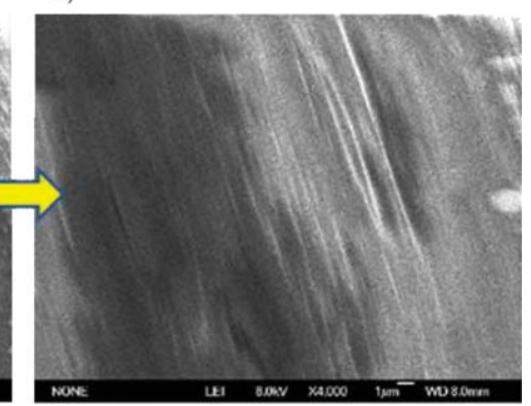

f)

Figure 2. FE-SEM images of E6C4 specimen: (a, b) etched surface; (c, d) tensile fractured surface; (e, f) longitudinal stretching surface. 


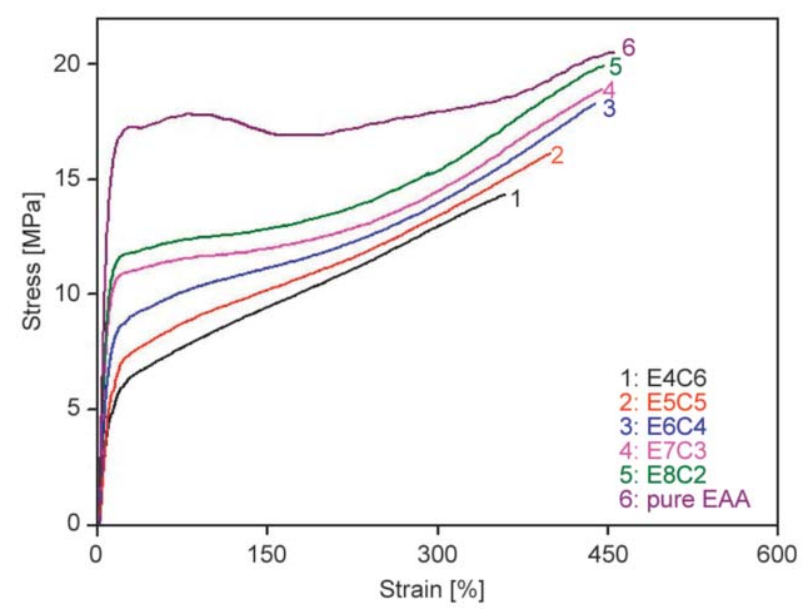

Figure 3. Stress-strain behaviors of EAA resin and EAA/CR TPVs.

similar in the curve shape. Initially, an increase in tensile stress could be observed, which was associated with the resisted deformation of EAA phase. Upon further deformation, the slope of the curve decreased while the stress increased almost linearly with strain. All the stress-strain curves of the EAA/ CR TPVs showed the representative elastomer character of softness and toughness. It could also be seen that the tensile strength and elongation at break were increased obviously with increasing the EAA phase, showing the good physical interaction between the EAA phase and the CR phase during stretching.

\subsection{Shape-memory performance of EAA/CR TPVs}

To give a direct cognition of the SME of EAA/CR TPVs, Figure 4 visually shows the typical heat-triggered shape-memory behavior of pure EAA and the E6C4 specimens in tensile, spiral and curling models.
The shape-memory recovery was achieved in hot oil while both $T_{\mathrm{d}}$ and $T_{\mathrm{r}}$ were set at $95^{\circ} \mathrm{C}$. $T_{\mathrm{d}}$ was set slightly below the $T_{\mathrm{m}}$ of the EAA resin $\left(106.4^{\circ} \mathrm{C}\right)$, because the TPV softening was realized by partial melting of the EAA crystal region, which was advantageous for fixing the temporary shape at this temperature. It is clearly seen that the original shape was recovered swiftly from different temporary shape even at the initial time ( $\sim 30 \mathrm{~s})$. It should be emphasized that the shapes 3-4 in Figure 4 were all derived from the same E6C4 sample; moreover, compared with that of the shapes 1-2 in Figure 4 from the same pure EAA, the EAA/CR TPV could exhibit excellent reprocessing and shape reconstruction ability in the shape-memory process. We envisioned that the fast recovery time and the excellent shape-memory property would bring potential applications of EAA/CR TPVs in sensors and self-disassembling intelligent devices [40].

To illustrate in-depth the relationship between $T_{\mathrm{d}}$ and shape-memory property of EAA/CR TPVs, Figure 5a shows the $S F$ and $S R$ ratios of the series of EAA/CR TPVs obtained at various $T_{\mathrm{d}}$ values while the $T_{\mathrm{r}}$ was set at $95^{\circ} \mathrm{C}$. Because the $T_{\mathrm{d}}$ was set at near the $T_{\mathrm{m}}$ value of the EAA phase, the melting of crystals in the EAA phase made the material soft for easy deformation and shaping. To give an overall understanding of the SME, we showed the results of $S F$ and $S R$ of TPVs with various EAA/CR weight ratios in Figure 5a. $S F$ and $S R$ showed a dependence on the EAA/CR weight ratios. From Figure 5a, the $S F$ ratio increased with the increasing EAA content in the EAA/CR TPVs, which indicated the $S F$ ability of the EAA/CR TPVs was mainly determined by the EAA
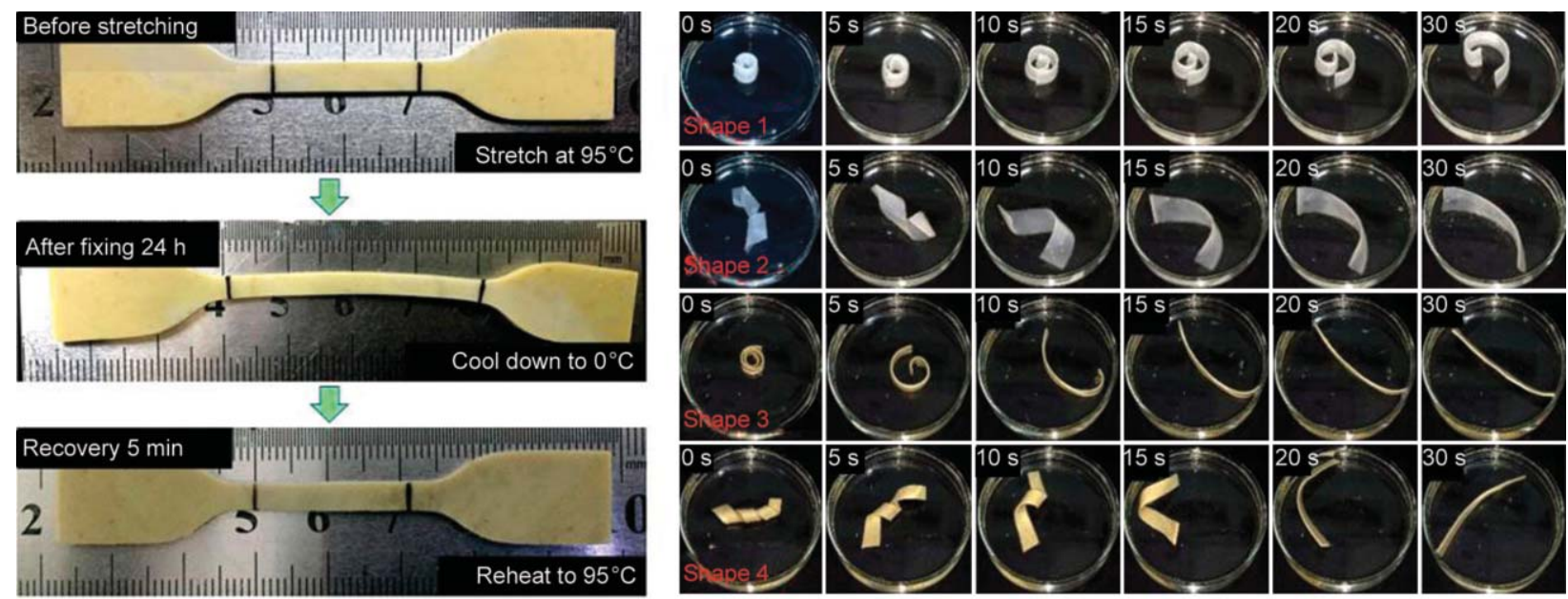

Figure 4. Shape-memory behavior in various modes for pure EAA and E6C4 while both $T_{\mathrm{d}}$ and $T_{\mathrm{r}}$ were set at $95^{\circ} \mathrm{C}$ : (Shape 1,2) pure EAA; (Shape 3,4) E6C4. 

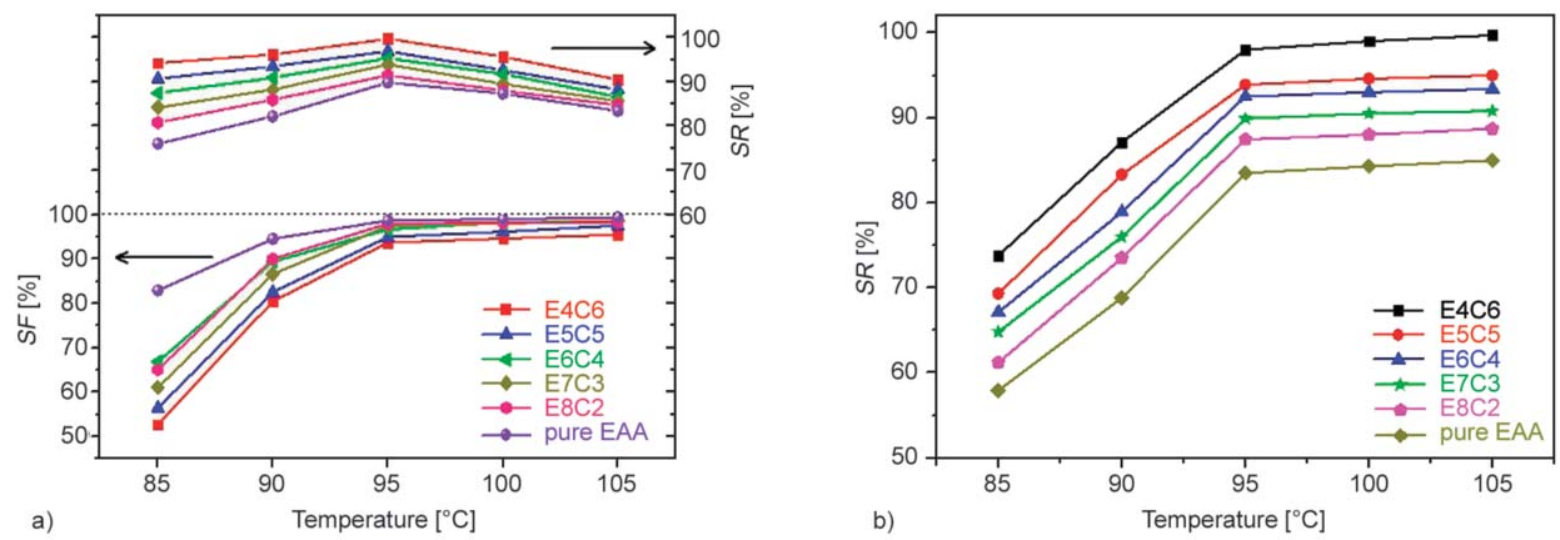

Figure 5. $S F$ and $S R$ ratios for pure EAA, the series of EAA/CR TPVs obtained: (a) at various $T_{\mathrm{d}}$ values $\left(T_{\mathrm{r}}=95^{\circ} \mathrm{C}\right)$; (b) at various $T_{\mathrm{r}}$ values $\left(T_{\mathrm{d}}=95^{\circ} \mathrm{C}\right)$.

matrix phase. The strain-crystallization phenomenon under constant load was achieved by the anomalous cooling-induced elongation in the semi-crystalline EAA phase [41], which was the main cause of the firm fixing of the elongated CR particles by the EAA molecular chain. It can also be seen from Figure 5a that the $S F$ ratio increased with increasing $T_{\mathrm{d}}$, which could be ascribed to the easier and faster rearrangement of EAA molecule chains at the higher $T_{\mathrm{d}}$, thereby forming an advanced continuous plastic phase to hold the temporary shape. However, when the $T_{\mathrm{d}}$ was too close to the $T_{\mathrm{m}}$ value, it may cause the melting of the majority crystals in the EAA phase, and the rubber particles no longer undergo deformation. The $T_{\mathrm{d}}$ value must be carefully selected to ensure that the EAA continuous phase has suffcient strength to deform the rubber particles. We could also see that it was worth pointing out that with increasing $T_{\mathrm{d}}$, the $S R$ ratios firstly increased and then decreased when $T_{\mathrm{d}}$ exceeded $95^{\circ} \mathrm{C}$, as shown in Figure $5 \mathrm{a}$. Meanwhile, the shape-memory effects reached a maximum value when the EAA content was $60 \mathrm{phr}$ (E6C4). A good interface between EAA and CR provided critical assistance in deforming or keeping the deformed rubber particles in temporary shape, storing suffcient resilience to fulfill the shape-memory performance [42-45]. These observations suggested that E6C4 with $\sim 97 \% S F$ and $\sim 95 \% S R\left(T_{\mathrm{d}}\right.$ at $\left.95^{\circ} \mathrm{C}\right)$ was an ideal candidate to expose its potential SME. Figure $5 \mathrm{~b}$ shows the $S R$ ratios for pure EAA, the series of EAA/CR TPVs obtained at various $T_{\mathrm{r}}$ values while the $T_{\mathrm{d}}$ was set at $95^{\circ} \mathrm{C}$. From Figure $5 \mathrm{~b}$, the $S R$ ratio of the EAA/CR TPVs increased with increasing CR content, which indicated the $S R$ driving force was mainly contributed by the CR phase in the TPVs.

\subsection{Differential scanning calorimeter of EAA/CR TPVs}

The thermal properties including the crystallization and melting behavior of the samples were characterized by DSC and the results were shown in Figure 6. Figures 6 illustrates the DSC heating scans of EAA resin and series of EAA/CR TPVs from -60 to $140^{\circ} \mathrm{C}$ at a heating rate of $20^{\circ} \mathrm{C} / \mathrm{min}$. The melting temperatures, enthalpy, and relative crystallinities are summarized in Table 2. The Equation (4) is used to calculate the degree of crystallinity in Table 2 :

$X_{\mathrm{c}}=\frac{\Delta H_{\mathrm{f}}}{\Delta H} \cdot \frac{1}{W_{\mathrm{f}}} \cdot 100 \%$

where $\Delta H_{\mathrm{f}}$ stands for crystallization enthalpy of the sample after testing, $\Delta H$ stands for crystallization enthalpy of the sample at the time of $100 \%$ crystallization $(\Delta H=298 \mathrm{~J} / \mathrm{g}), W_{\mathrm{f}}$ stands for the proportion of crystalline substances in the mixture.

All the DSC thermograms for the blends showed two distinctive peaks. The heats of melting transition in the TPVs increased as the fraction of EAA increased. A plot of reversing heat flow and temperature from modulated DSC revealed that the $T_{\mathrm{m}}$ and $T_{\mathrm{c}}$ of series EAA/CR TPVs and pure EAA was $102.7 \sim 106.4^{\circ} \mathrm{C}$

Table 2. $\Delta H_{\mathrm{f}}, X_{\mathrm{c}}$ and $T_{\mathrm{m}}$ of dynamically vulcanized EAA/CR blends measured by DSC.

\begin{tabular}{|l|c|c|c|c|}
\hline $\begin{array}{c}\text { EAA/CR } \\
\text { [weight ratio] }\end{array}$ & $\begin{array}{c}\boldsymbol{m} \\
{[\mathbf{m g}]}\end{array}$ & $\begin{array}{c}\Delta \boldsymbol{H}_{\mathbf{f}} \\
{[\mathbf{J} / \mathbf{g}]}\end{array}$ & $\begin{array}{c}\boldsymbol{X}_{\mathbf{c}} \\
{[\mathbf{\%}]}\end{array}$ & $\begin{array}{c}\boldsymbol{T}_{\mathbf{m}} \\
{\left[{ }^{\circ} \mathbf{C}\right]}\end{array}$ \\
\hline $40 / 60$ & 5.70 & 23.16 & 19.43 & 102.74 \\
\hline $50 / 50$ & 6.90 & 35.43 & 23.78 & 102.90 \\
\hline $60 / 40$ & 6.00 & 44.13 & 24.68 & 103.56 \\
\hline $70 / 30$ & 5.50 & 50.13 & 24.03 & 105.22 \\
\hline $80 / 20$ & 5.40 & 57.32 & 24.04 & 105.86 \\
\hline Pure EAA & 6.20 & 79.99 & 26.84 & 106.49 \\
\hline
\end{tabular}



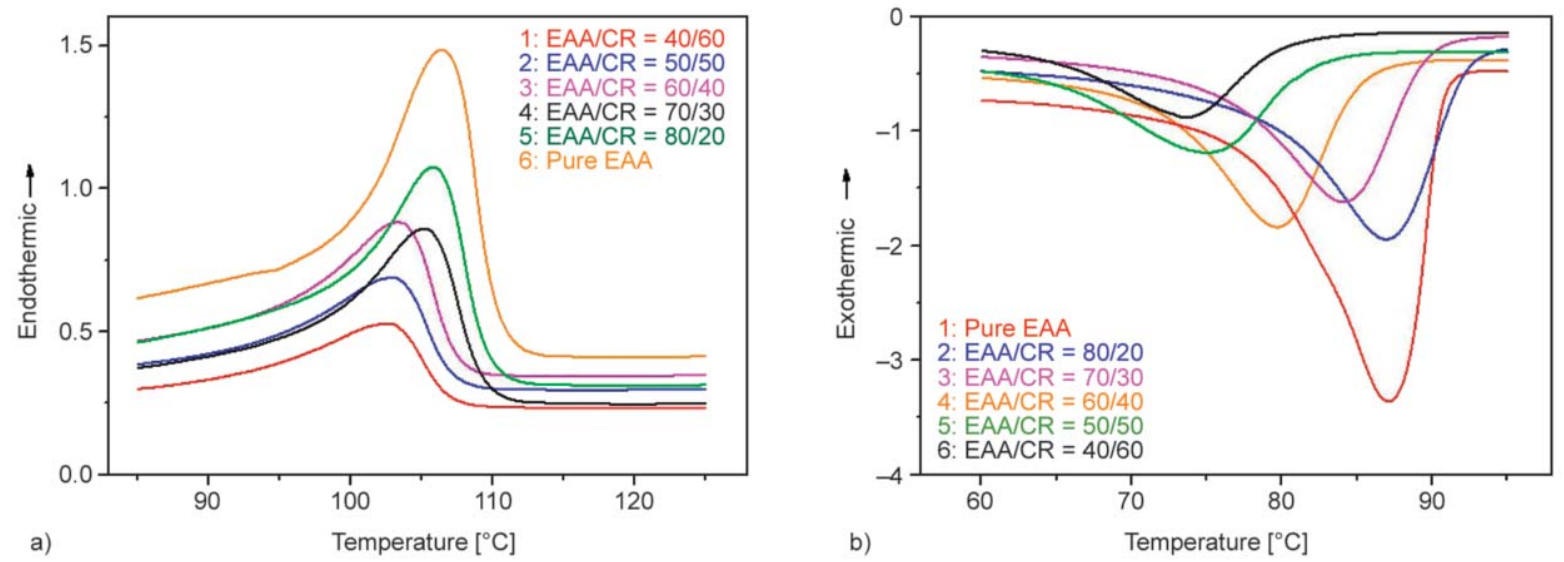

a)

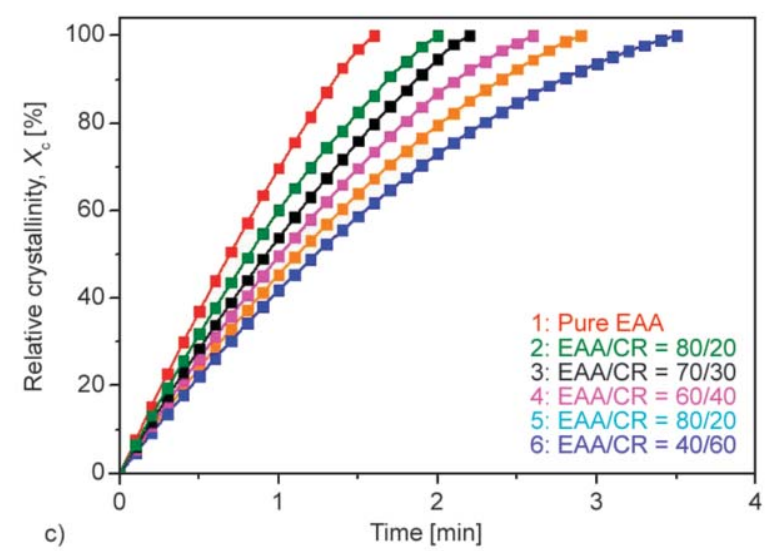

Figure 6. DSC thermograms of pure EAA and series of EAA/CR TPVs: (a) heating curves; (b) cooling curves; (c) relative crystallinity.

and $80.19 \sim 90.60^{\circ} \mathrm{C}$, respectively. With the increasing of EAA content, the hydrogen bonds in the carboxyl group increased, and motor ability of chain segments decreased. Moreover, the hydrogen bonds in carboxyl groups were dissociated with the increase of temperature, and the TPV was easy to crystallize. It is obviously to find that the crystallization of EAA was inhibited by $\mathrm{CR}$, that is to say, the aggregation and arrangement of EAA sub-chain were hindered by $\mathrm{CR}$ molecular chain, resulting in the increasing crystal defects and the decreasing crystal content and $T_{\mathrm{m}}$.

\subsection{X-ray diffraction of EAA/CR TPVs}

XRD patterns of pure EAA, zinc oxide $(\mathrm{ZnO})$ powder, Magnesium oxide $(\mathrm{MgO})$ powder and series of EAA/CR blends are shown in Figure 7. For the pure EAA, three perceptible diffractive peaks have been observed around $21.28,23.62$ and $36.08^{\circ}$ corresponding to the typical (110), (200) and (020) crystallographic planes of polyethylene, indicating EAA has an orthorhombic unit cell structure and its (110) crystallographic plane has the strongest diffraction intensity [46]. Moreover, the characteristic reflections of EAA/CR TPVs corresponded to those of EAA, $\mathrm{MgO}$, and $\mathrm{ZnO}$. Compared to the XRD curves of pure EAA, series of EAA/CR TPVs would reduce the intensity of diffractive peak with the increasing of CR content, indicating the decreasing crystalline structure content in EAA. Meanwhile, with the increase of EAA content, the intensity of crystal diffraction peak tends to increase at the (110) crystallographic plane.

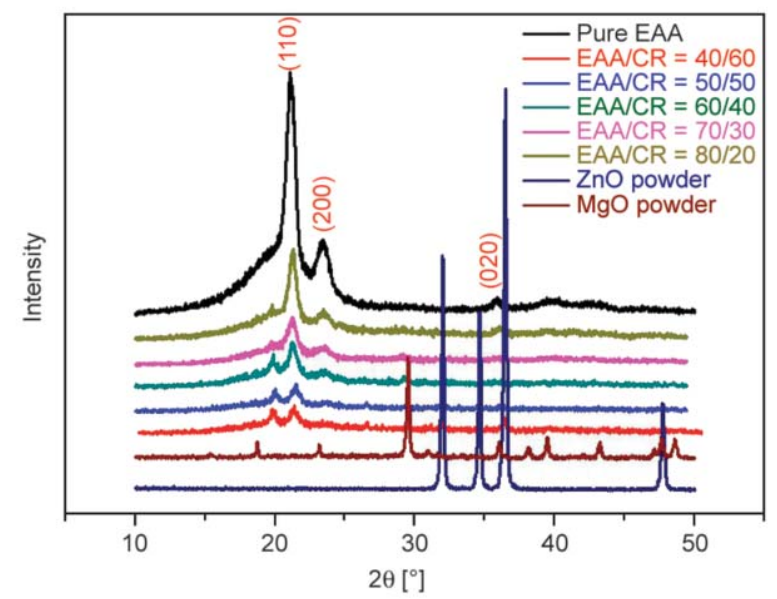

Figure 7. XRD patterns of pure EAA, $\mathrm{ZnO}$ powder, $\mathrm{MgO}$ powder and the series of EAA/CR TPVs. 


\subsection{Dynamic mechanical analysis of EAA/CR TPVs}

Dynamic mechanical behaviors of the EAA/CR TPVs were conducted by DMA, which contributed to the deep influencing of the viscoelastic behavior on the shape-memory capability for EAA/CR TPVs.

The $\tan \delta$ and $E^{\prime}$ as a function of the temperature is shown in Figure 8, respectively. Figure 8a shows the temperature dependence of $\tan \delta$ of EAA resin, CR vulcanizate, and EAA/CR TPVs. From Figure 8a, it can be observed that the $T_{\mathrm{g}}$ values of EAA and CR were all much below than room temperature; moreover, the difference between their $T_{\mathrm{g}}$ values was not so large. As a result, the series of EAA/CR TPVs had a single $T_{\mathrm{g}}$ value, which suggested the EAA and CR were well miscible. The $T_{\mathrm{d}}$ was determined from the peak of $\tan \delta$ in Figure 8a. In detail, as the weight ratio of EAA/CR increased from 40/60 to $80 / 20$, the $T_{\mathrm{g}}$ value of EAA/CR TPVs was shifted from $-29.68^{\circ} \mathrm{C}$ (E4C6) to $-31.91{ }^{\circ} \mathrm{C}(\mathrm{E} 8 \mathrm{C} 2)$, correspondingly. It can be also explained by the higher mobility and dynamic transition of the CR chain segments. Figure $8 \mathrm{~b}$ shows the temperature dependence of the E' values of EAA resin, CR vulcanizate, and EAA/CR TPVs. We could see from Figure $8 b$ that the glass transition area of CR vulcanizate was a sharp decrease in the area of -40 to $0^{\circ} \mathrm{C}$. One distinct phenomenon was evident that the $E^{\prime}$ values of the TPVs containing higher EAA were always higher than that of the TPVs containing lower EAA in the temperature range of $-60 \sim 100^{\circ} \mathrm{C}$, which can be explained by the higher modulus of pure EAA. It was believed that the enhanced $E^{\prime}$ would promote the EAA phase to deform the $\mathrm{CR}$ particles and hence promote the $\mathrm{CR}$ particles to store sufficient elastic restoring force for shape recovery [47]. Based on the above dynamic

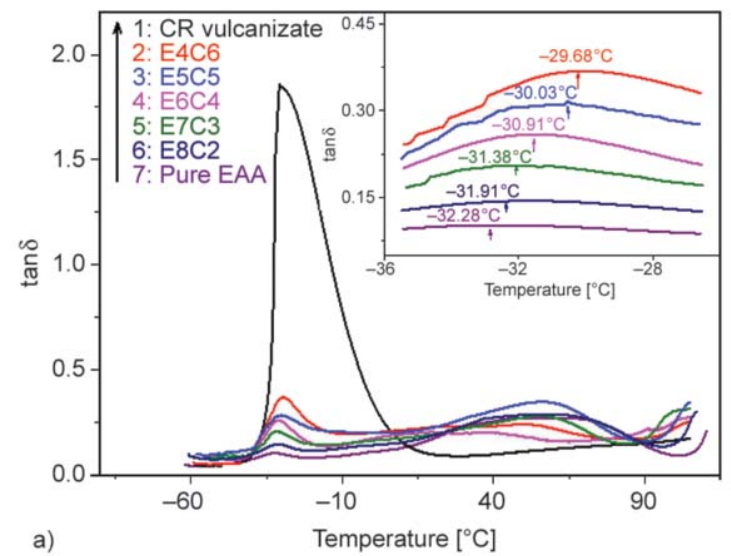

mechanical analysis, the DMA results provided an accessible way for us to tune SME of the TPVs by adjusting EAA/CR weight ratio, and also supported our strategy for designing shape-memory TPVs.

In order to understand the shape-memory mechanism of EAA/CR TPVs clearly, we studied the stressstrain curves of E6C4 specimens at 25, 65, 80, 95 and $110^{\circ} \mathrm{C}$ and further presented a simple illustration of the deformation state of the CR particles in the EAA phase in Figure 9. As shown in Figure 9, the stress-strain curve of the $\mathrm{E} 6 \mathrm{C} 4$ at $25^{\circ} \mathrm{C}$ (room temperature) showed the elastomer character of soft and tough. When the test temperature was 65 and $80^{\circ} \mathrm{C}$ (below the $T_{\mathrm{m}}$ of EAA), both the tensile strength and the elongation at break of E6C4 decreased, which could be attributed to the enhanced activity of the chains and the reduced physical entanglements of chains in the EAA amorphous phase, although the majority of the EAA molecule chains were still in frozen state at this time. When the test temperature was $95^{\circ} \mathrm{C}$ (near but still below the $T_{\mathrm{m}}$ of EAA), the partial melting of the EAA crystal region made the TPV soften, and the deformation of TPV could be realized easily under the external force, resulting in high $S F$ ratios; meanwhile, the dispersed CR particles were elongated and well fixed by the subsequent rapid cooling. As a result, the resilient force stored in CR particles driven the TPV to fulfill the shape recovery effectively. When the test temperature was $110^{\circ} \mathrm{C}$, the most crystal region of the EAA melted so that the EAA lost most of its strength, which resulted in the large deformation of the TPV under external force and the high $S F$ ratio; however, the softened EAA phase can not fix CR particles forcefully through the EAA/CR interface at this temperature, leading to the very weak resilience force stored in

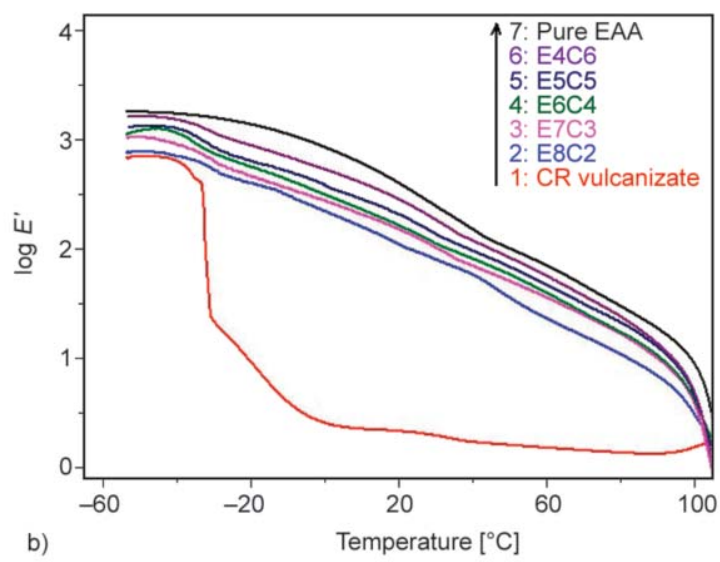

Figure 8. DMA results of various EAA/CR TPVs: (a) $\tan \delta$; (b) $\log E^{\prime}$. 


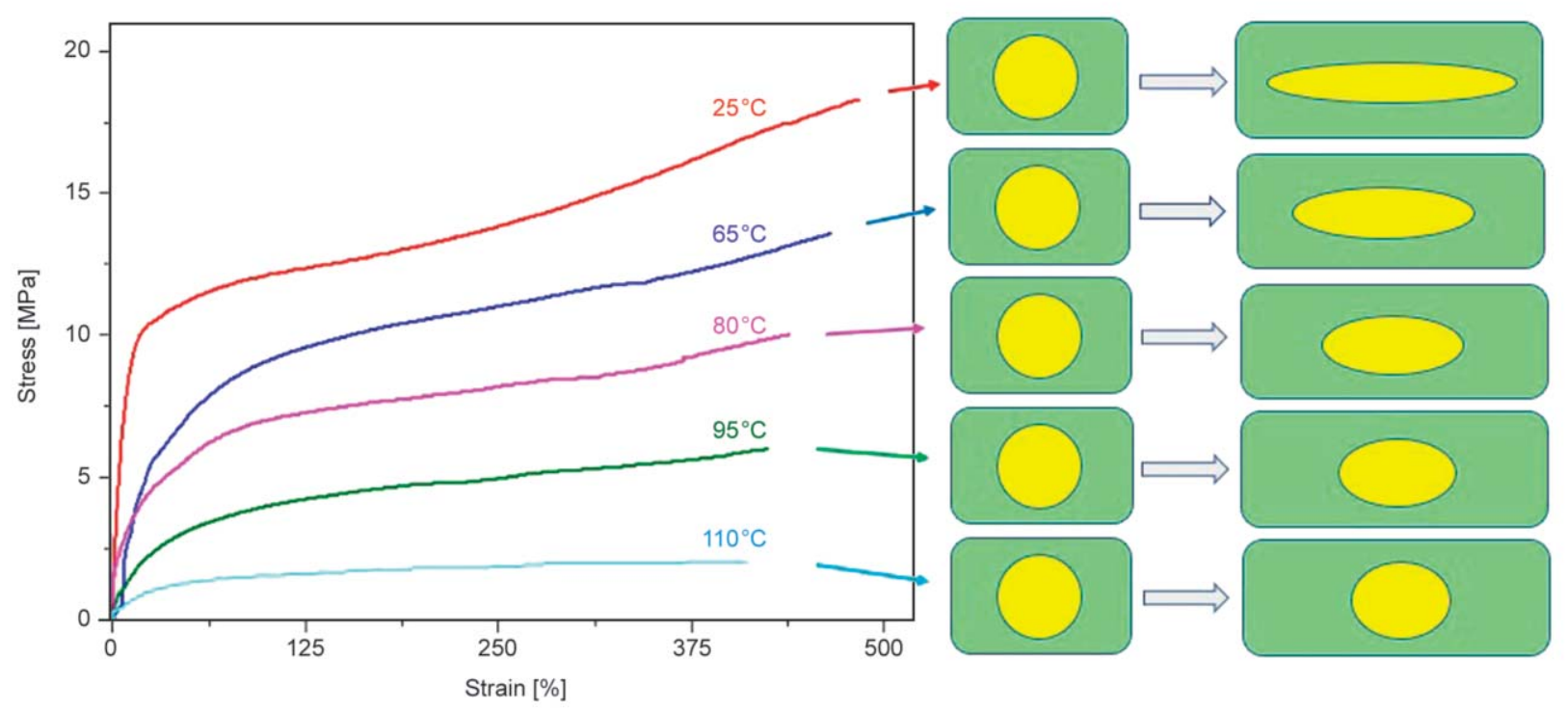

Figure 9. Stress-strain curves of E6C4 specimens at 25, 65, 80, 95 and $110^{\circ} \mathrm{C}$ and a simple illustration of the deformation state of the CR particles in the EAA phase.

the deformed CR particles and the low $S R$. In Xu's report [33], a strong interface originating from in situ compatibilization was critical to the $S R$ of EPDM/ PP/ZDMA TPVs. Altogether, these results show that SME can be achieved in the EPDM/PP/ZDMA system with an improved interface at a suitable $T_{\mathrm{d}}$ value. Compared with that of the Xu's report, even without zinc dimethacrylate induced interfacial compatibilization, the EAA/CR TPVs in our research have a strong interface adhesion and the high mechanical properties.

\subsection{Stress relaxation behaviors of EAA/CR TPVs}

It is important to recognize that, in a shape recovery process, the shape recovery driving force is mainly derived from the stress-energy stored inside the

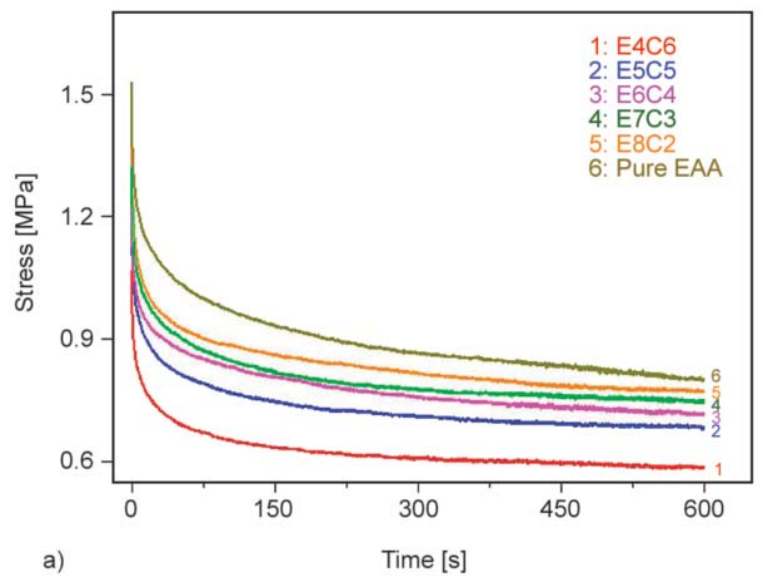

HSMPs during the shape fixing step [14, 47]. Although the exact correlation between the stored stressenergy and the energy required in the deformation is not known (i.e. the amount of energy loss during the shape fixing step is not known), the research on the qualitative correlation between the stress relaxation and the shape recovery capability still has important reference significance. It is well known that the force required to maintain a constant strain that is applied to a viscoelastic material gradually decreases with time and this phenomenon is called 'stress relaxation'. Figure 10 depicts the stress relaxation and stress relaxation ratio versus time curves of the various EAA/CR TPVs at $95^{\circ} \mathrm{C}$. From Figures 10, it could be noticed obviously that, the stress relaxation curve platform (stress level) increased with increasing the EAA dosage in the EAA/CR TPVs, which was

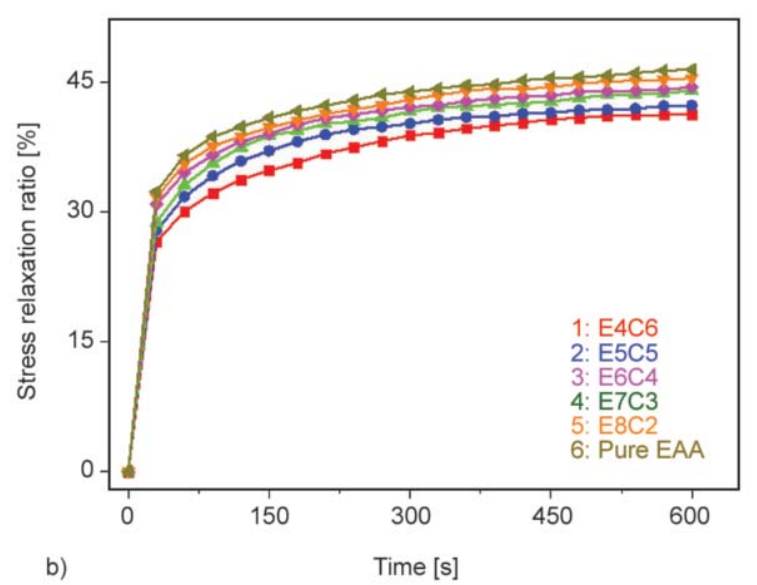

Figure 10. Pure EAA and the series EAA/CR TPVs in tensile mode at $95^{\circ} \mathrm{C}$ : (a) stress relaxation versus time curves; (b) stress relaxation ratio versus time. 
consistent with the DMA results (Figure 8b). At the same time, it was inevitable that higher levels of EAA increased the stress relaxation ratios of the EAA/CR TPVs and also led to an easier shape fixation and fewer restricted $C R$ particles which were responsible for storing most of the elastic restoring force. Meanwhile, it could be interpreted as the molecular slip of EAA and CR phase via molecular segment conformational adjustment, which may also be the reason why the $S F$ ratios of EAA/CR TPVs in Figure $5 \mathrm{~b}$ increased at high EAA dosage. It was worth stating that all the results of stress relaxation behavior supported the shape-memory behavior of the EAA/CR TPV systems in Figure 5.

\section{Conclusions}

A valuable strategy for facile designing HSMPs based EAA/CR TPVs, which has been reported in this work. This strategy has the potential for large-scale fabrication as the shape-memory EAA/CR TPVs are easily post-processed by existed apparatuses, and its straightforward raw materials are industrially supplied and recyclable at low cost. Shape-memory and DMA studies showed, for this type of HSMPs, the strong interaction between the EAA and CR phase and the appropriate EAA/CR ratios were the keys to the excellent shape-memory performance. Meanwhile, DSC and XRD studies also showed that EAA/ CR TPVs had some unexpected crystallization attributes, endow SMPs with tremendous tunability in terms of switching temperature and energy, and high strain fixity and recovery levels. Mechanical properties and stress relaxation behavior studies showed that better shape-memory behavior of the EAA/CR TPVs was also supported by the adequate stress level and lower degree of the stress relaxation ratio of the TPVs.

\section{Acknowledgements}

The work was supported by the Shandong Provincial Natural Science Foundation, China (ZR2017MEM021) and an Upgraded Project of Shandong Province for Guidance Ability of Graduate Tutors (SDYY17044).

\section{References}

[1] Sun L., Huang W. M., Ding Z., Zhao Y., Wang C. C., Purnawali H., Tang C.: Stimulus-responsive shape memory materials: A review. Materials and Design, 33, 577 640 (2012).

https://doi.org/10.1016/j.matdes.2011.04.065
[2] Behl M., Razzaq M. Y., Lendlein A.: Multifunctional shape-memory polymers. Advanced Materials, 22, 3388-3410 (2010). https://doi.org/10.1002/adma.200904447

[3] Serrano M. C., Carbajal L., Ameer G. A.: Novel biodegradable shape-memory elastomers with drug-releasing capabilities. Advanced Materials, 23, 2211-2215 (2011). https://doi.org/10.1002/adma.201004566

[4] Heo Y., Sodano H. A.: Self-healing polyurethanes with shape recovery. Advanced Functional Materials, 24, 5261-5268 (2014).

https://doi.org/10.1002/adfm.201400299

[5] Hu J., Chen S.: A review of actively moving polymers in textile applications. Journal of Materials Chemistry, 20, 3346-3355 (2010).

https://doi.org/10.1039/B922872A

[6] Maksimkin A. V., Kaloshkin S. D., Zadorozhnyy M. V., Senatov F. S., Salimon A. I., Dayyoub T.: Artificial muscles based on coiled UHMWPE fibers with shape memory effect. Express Polymer Letters, 12, 1072-1080 (2018).

https://doi.org/10.3144/expresspolymlett.2018.94

[7] Yu Z. Y., Li Y., Feng Z. P., Zhang Z. H., Li P., Chen Y., Chen S. S., Li P. W., Yang Z. M.: Cu+-containing physically crosslinked chitosan hydrogels with shape memory. Express Polymer Letters, 13, 785-793 (2019).

https://doi.org/10.3144/expresspolymlett.2019.67

[8] Fang Z., Zheng N., Zhao Q., Xie T.: Healable, reconfigurable, reprocessable thermoset shape memory polymer with highly tunable topological rearrangement kinetics. ACS Applied Materials and Interfaces, 9, 2207722082 (2017).

https://doi.org/10.1021/acsami.7b05713

[9] Robertson J. M., Nejad H. B., Mather P. T.: Dual-spun shape memory elastomeric composites. ACS Macro Letters, 4, 436-440 (2015). https://doi.org/10.1021/acsmacrolett.5b00106

[10] Zhao Q., Qi H. J., Xie T.: Recent progress in shape memory polymer: New behavior, enabling materials, and mechanistic understanding. Progress in Polymer Science, 49, 79-120 (2015). https://doi.org/10.1016/j.progpolymsci.2015.04.001

[11] Xu C., Wu W., Zheng Z., Wang Z., Nie J.: Design of shape-memory materials based on sea-island structured EPDM/PP TPVs via in-situ compatibilization of methacrylic acid and excess zinc oxide nanoparticles. Composites Science and Technology, 167, 431-439 (2018). https://doi.org/10.1016/j.compscitech.2018.08.038

[12] Fan L. F., Rong M. Z., Zhang M. Q., Chen X. D.: Repeated intrinsic self-healing of wider cracks in polymer via dynamic reversible covalent bonding molecularly combined with a two-way shape memory effect. ACS Applied Materials and Interfaces, 10, 38538-38546 (2018). https://doi.org/10.1021/acsami.8b15636 
[13] Huang J., Cao L., Yuan D., Chen Y.: Design of multistimuli-responsive shape memory biobased PLA/ENR/ $\mathrm{Fe}_{3} \mathrm{O}_{4}$ TPVs with balanced stiffness-toughness based on selective distribution of $\mathrm{Fe}_{3} \mathrm{O}_{4}$. ACS Sustainable Chemistry and Engineering, 7, 2304-2315 (2018). https://doi.org/10.1021/acssuschemeng.8b05025

[14] Xie T.: Recent advances in polymer shape memory. Polymer, 52, 4985-5000 (2011). https://doi.org/10.1016/j.polymer.2011.08.003

[15] Mather P. T., Luo X., Rousseau I. A.: Shape memory polymer research. Annual Review of Materials Research, 39, 445-471 (2009).

https://doi.org/10.1146/annurev-matsci-082908-145419

[16] Meng Q., Hu J.: A review of shape memory polymer composites and blends. Composites Part A: Applied Science and Manufacturing, 40, 1661-1672 (2009). https://doi.org/10.1016/j.compositesa.2009.08.011

[17] Kratz K., Voigt U., Lendlein A.: Temperature-memory effect of copolyesterurethanes and their application potential in minimally invasive medical technologies. Advanced Functional Materials, 22, 3057-3065 (2012). https://doi.org/10.1002/adfm.201200211

[18] Mineart K. P., Tallury S. S., Li T., Lee B., Spontak R. J.: Phase-change thermoplastic elastomer blends for tunable shape memory by physical design. ACS Industrial and Engineering Chemistry Research, 55, 12590 12597 (2016). https://doi.org/10.1021/acs.iecr.6b04039

[19] Ratna D., Karger-Kocsis J.: Recent advances in shape memory polymers and composites: A review. Journal of Materials Science, 43, 254-269 (2008). https://doi.org/10.1007/s10853-007-2176-7

[20] Samuel C., Barrau S., Lefebvre J-M., Raquez J-M., Dubois P.: Designing multiple-shape memory polymers with miscible polymer blends: Evidence and origins of a triple-shape memory effect for miscible PLLA/ PMMA blends. Macromolecules, 47, 6791-6803 (2014). https://doi.org/10.1021/ma500846x

[21] Suchao-in K., Chirachanchai S.: 'Grafting to' as a novel and simple approach for triple-shape memory polymers. ACS Applied Materials and Interfaces, 5, 6850 6853 (2013). https://doi.org/10.1021/am402214j

[22] Wang C. C., Huang W. H., Ding Z., Zhao Y., Purnawali H.: Cooling-/water-responsive shape memory hybrids. Composites Science and Technology, 72, 1178-1182 (2012). https://doi.org/10.1016/j.compscitech.2012.03.027

[23] Julich-Gruner K. K., Löwenberg C., Neffe A., Behl M., Lendlein A.: Recent trends in the chemistry of shapememory polymers. Macromolecular Chemistry and Physics, 214, 527-536 (2013).

https://doi.org/10.1002/macp.201200607
[24] Lashgari S., Karrabi M., Ghasemi I., Azizi H., Messori M., Paderni K.: Shape memory nanocomposite of poly(L-lactic acid)/graphene nanoplatelets triggered by infrared light and thermal heating. Express Polymer Letters, 10, 349-359 (2016).

https://doi.org/10.3144/expresspolymlett.2016.32

[25] Bao M., Lou X., Zhou Q., Dong W., Yuan H., Zhang Y.: Electrospun biomimetic fibrous scaffold from shape memory polymer of PDLLA-co-TMC for bone tissue engineering. ACS Applied Materials and Interfaces, 6, 2611-2621 (2014). https://doi.org/10.1021/am405101k

[26] Chen H., Cao X., Zhang J., Zhang J., Ma Y., Shi G., Ke Y., Tong D., Jiang L.: Electrospun shape memory film with reversible fibrous structure. Journal of Materials Chemistry, 22, 22387-22391 (2012). https://doi.org/10.1039/c2jm33970f

[27] Tanpitaksit T., Jubsilp C., Rimdusit S.: Effects of benzoxazine resin on property enhancement of shape memory epoxy: A dual function of benzoxazine resin as a curing agent and a stable network segment. Express Polymer Letters, 9, 824-837 (2015).

https://doi.org/10.3144/expresspolymlett.2015.77

[28] Chen Y., Yuan D., Xu C.: Dynamically vulcanized biobased polylactide/natural rubber blend material with continuous cross-linked rubber phase. ACS Applied Materials and Interfaces, 6, 3811-3816 (2014). https://doi.org/10.1021/am5004766

[29] Chen Y., Xu C., Liang X., Cao L.:In situ reactive compatibilization of polypropylene/ethylene-propylenediene monomer thermoplastic vulcanizate by zinc dimethacrylate via peroxide-induced dynamic vulcanization. The Journal of Physical Chemistry B, 117, 1061910628 (2013). https://doi.org/10.1021/jp404427w

[30] Yuan D., Chen Z., Xu C., Chen K., Chen Y.: Fully biobased shape memory material based on novel cocontinuous structure in poly(lactic acid)/natural rubber TPVs fabricated via peroxide-induced dynamic vulcanization and in situ interfacial compatibilization. ACS Sustainable Chemistry and Engineering, 3, 2856-2865 (2015). https://doi.org/10.1021/acssuschemeng.5b00788

[31] Ma P., Xu P., Liu W., Zhai Y., Dong W., Zhang Y., Chen M.: Bio-based poly(lactide)/ethylene-co-vinyl acetate thermoplastic vulcanizates by dynamic crosslinking: Structure vs. property. RSC Advances, 5, 15962-15968 (2015). https://doi.org/10.1039/C4RA14194F

[32] Kolesov I., Dolynchuk O., Radusch H-J.: Shape-memory behavior of cross-linked semi-crystalline polymers and their blends. Express Polymer Letters, 9, 255-276 (2015). https://doi.org/10.3144/expresspolymlett.2015.24 
[33] Xu C., Lin B., Liang X., Chen Y.: Zinc dimethacrylate induced in situ interfacial compatibilization turns EPDM/PP TPVs into a shape memory material. Industrial and Engineering Chemistry Research, 55, 45394548 (2016). https://doi.org/10.1021/acs.iecr.6b00612

[34] Scaffaro R., La Mantia F. P., Castronovo C.: Reactive compatibilization of PBT/EVA blends with an ethyleneacrylic acid copolymer and a low molar mass bis-oxazoline. Macromolecular Chemistry and Physics, 205, 1402-1409 (2004). https://doi.org/10.1002/macp.200400059

[35] Scaffaro R., La Mantia F. P., Canfora L., Polacco G., Filippi S., Magagnini P.: Reactive compatibilization of PA6/LDPE blends with an ethylene-acrylic acid copolymer and a low molar mass bis-oxazoline. Macromolecular Chemistry and Physics, 44, 6951-6957 (2003). https://doi.org/10.1016/j.polymer.2003.06.001

[36] Liu J., Zhang Y.: Effect of ethylene-acrylic acid copolymer on flame retardancy and properties of LDPE/EAA/ MH composites. Polymer Degradation and Stability, 96, 2215-2220 (2011). https://doi.org/10.1016/j.polymdegradstab.2011.09.010

[37] Kim B., Lee S. B., Lee J., Cho S., Park H., Yeom S., Park S. H.: A comparison among neo-hookean model, mooney-rivlin model, and ogden model for chloroprene rubber. International Journal of Precision Engineering and Manufacturing, 13, 759-764 (2012). https://doi.org/10.1007/s12541-012-0099-y

[38] Kuahara H., Sudo S., Iijima M., Ohya S.: Dielectric properties of thermally degraded chloroprene rubber. Polymer Degradation and Stability, 95, 2461-2466 (2010). https://doi.org/10.1016/j.polymdegradstab.2010.08.003

[39] Bengtsson P., Klason C., Kubat J., McQueen D. H.: Electrical noise characteristics of carbon-black-filled chloroprene rubber. Journal of Physics D: Applied Physics, 22, 1736-1740 (2000). https://doi.org/10.1088/0022-3727/22/11/026

[40] Pilate F., Toncheva A., Dubois P., Raquez J-M.: Shapememory polymers for multiple applications in the materials world. European Polymer Journal, 80, 268-294 (2016). https://doi.org/10.1016/j.eurpolymj.2016.05.004
[41] Chung T., Rorno-Uribe A., Mather P.: Two-way reversible shape memory in a semicrystalline network. Macromolecules, 41, 184-192 (2008).

https://doi.org/10.1021/ma071517z

[42] Khodabandelou M., Razavi Aghjeh M. K., Mazidi M. M.: Fracture toughness and failure mechanisms in unvulcanized and dynamically vulcanized PP/EPDM/ MWCNT blend-nanocomposites. RSC Advances, 5, 70817-70831 (2015). https://doi.org/10.1039/c5ra12087j

[43] Lu X., Wei X., Huang J., Yang L., Zhang G., He H., Wang M., Qu J.: Supertoughened poly(lactic acid)/polyurethane blend material by in situ reactive interfacial compatibilization via dynamic vulcanization. Industrial and Engineering Chemistry Research, 53, 17386-17393 (2014). https://doi.org/10.1021/ie503092w

[44] Liu H., Song W., Chen F., Guo L., Zhang J.: Interaction of microstructure and interfacial adhesion on impact performance of polylactide (PLA) ternary blends. Macromolecules, 44, 1513-1522 (2011). https://doi.org/10.1021/ma1026934

[45] Biju R., Gouri C., Reghunadhan-Nair C. P. R.: Shape memory polymers based on cyanate ester-epoxy-poly (tetramethyleneoxide) co-reacted system. European Polymer Journal, 48, 499-511 (2012). https://doi.org/10.1016/j.eurpolymj.2011.11.019

[46] Shi X-M., Zhang J., Li D-R., Chen S-J.: Effect of dampheat aging on the structures and properties of ethylenevinyl acetate copolymers with different vinyl acetate contents. Journal of Applied Polymer Science, 112, 2358-2365 (2009). https://doi.org/10.1002/app.29659

[47] Chen Y., Chen K., Wang Y., Xu C.: Biobased heat-triggered shape-memory polymers based on polylactide/ epoxidized natural rubber blend system fabricated via peroxide-induced dynamic vulcanization: $C o$-continuous phase structure, shape memory behavior, and interfacial compatibilization. ACS Industrial and Engineering Chemistry Research, 54, 8723-8731 (2015). https://doi.org/10.1021/acs.iecr.5b02195 